Recebido em 07.01.2019. Aprovado em 19.01.2019. Avaliado pelo sistema dableblindpeer review Publicado conforme normas da APA. http://dx.doi.org/10.22279/navus.2019.v9n3.p85-97.892

\title{
Características essenciais do microempreendedor individual de Boa Vista - RR
}

\author{
Eduardo Codevilla Soares Mestre em Administração. Pontifícia Universidade Católica do Rio Grande do Sul (PUCRS) - \\ Brasil.eduardo.soares@ufrr.br \\ Daniel Alves da Rocha Araújo Bacharel em Ciências Contábeis. Universidade Federal de Roraima (UFRR) - Brasil. \\ dgsavana@hotmail.com \\ Victor Emanuel de Jesus Belém Bacharel em Ciências Contábeis. Universidade Federal de Roraima (UFRR) - Brasil. \\ victorbelem17@hotmail.com \\ Wellerson Costa Pinho Bacharel em Ciências Contábeis. Universidade Federal de Roraima (UFRR) - Brasil. \\ wellerson.pinho@gmail.com
}

\section{RESUMO}

0 presente estudo tem o objetivo de analisar as características essenciais do microempreendedor individual de Boa Vista - RR. A pesquisa possui linha qualitativa exploratória. A seleção de entrevistados baseou-se por conveniência. Entrevistou-se doze profissionais, divididos em três categorias: analistas do SEBRAE, MEls e contadores. O levantamento de dados deu-se por meio de entrevista semiestruturada e analisado pelo conteúdo das respostas. Os resultados permitiram destacar que as características planejamento, detecção de oportunidade, sociabilidade, inovação, assunção de riscos calculados, persistência, além de determinação, audácia e busca por informações são essenciais ao Microempreendedor Individual boa-vistense. Recomendase que em pesquisa futura, a mesma seja reaplicada em outros munícipios de Roraima criando, assim, um panorama estadual do MEl. Ou ainda, sugere-se que a mesma seja desenvolvida utilizando o método quantitativo, com objetivo de verificar se a estrutura de análise proposta se aplica aos MEls de Boa Vista-RR de forma mais ampla.

Palavras-chave: MEl. Empreendedorismo. Perfil Empreendedor.

\section{Essential characteristics of the individual micro entrepreneur of Boa Vista - RR}

\begin{abstract}
This study aims at analyzing the essential characteristics of the Individual Micro-Entrepreneur (IME) of Boa Vista, Roraima. The study of the characteristics of the Individual Micro Entrepreneur- IME and it is of exploratory/qualitative nature. The selection of interviewees was on convenience. Twelve professionals were interviewed, divided in three categories: analysts of SEBRAE, IME's and accountants. The data was collected through semi-structured interview and analyzed by the content of the answers. The results allowed to highlight that the characteristics planning, opportunity detection, sociability, innovation, assumption of calculated risks, persistence, besides determination, audacity and search for information is essential to Individual Micro-Entrepreneurs of Boa Vista. It is recommended that in further research, it be reapplied in the cities of Roraima creating, this way, a state panorama of IME. Also, it is suggested for the research to be developed using the quantitative method, with the goal of verifying if the proposed analyses structure is applied to the IME's of Boa Vista-RR in a wider range.
\end{abstract}

Keywords: IME. Entrepreneurship. Entrepreneur Profile. 


\section{INTRODUÇÃO}

O mercado informal vem ganhando maior participação na economia ao longo dos anos. Nos países emergentes e em desenvolvimento, como o caso do Brasil, conforme aponta a ILO (2018), aproximadamente $60,7 \%$ dos trabalhadores exercem suas atividades de maneira informal, e, portanto, se encontram desamparados pela legislação trabalhista e previdenciária. Para Oliveira (2005), no Brasil, entre as décadas de 1980 e 1990, o trabalho informal cresceu além do esperado constituindo-se em um modo de inclusão ao mercado de trabalho, ao qual o mercado formal viu-se incapaz de absorver.

Conforme o Instituto Brasileiro de Geografia e Estatística - IBGE (2008), à época, o Brasil possuía aproximadamente mais de dez milhões de pessoas que trabalhavam de modo informal, os quais não possuíam os benefícios existentes na Consolidação das Leis do Trabalho - CLT como o Fundo de Garantia por Tempo de Serviço-FGTS, não realizavam contribuição à Seguridade Social, e nem eram amparados por vários direitos inerentes aos trabalhadores formalmente empregados.

Tendo em vista essa realidade, os legisladores brasileiros criaram a Lei Complementar no 128/2008, que passou a vigorar em julho de 2009. Nesta lei havia a proposição de uma nova forma de empresa, 0 Microempreendedor Individual-MEl, este tipo de empresa, segundo o Serviço Brasileiro de Apoio às Micro e Pequenas Empresas-SEBRAE (2018), é oriundo em maioria de pessoas que trabalham por conta própria e que se legalizam como pequenos empresários.

De acordo com a Lei Complementar no 128/2008, para ser um microempreendedor individual, é necessário faturar no máximo oitenta e um mil reais por ano e não ter participação em outra empresa como sócio ou titular.

No Brasil, conforme a Receita Federal (2018), existem 7.011.328 MEls, sendo 10.815 MEls em Roraima, conforme o SEBRAE (2016), em 2015 existiam 5.680.614 MEls e em Roraima 10.637 MEls em atividade, cenário que é capaz de apontar o crescimento quantitativo deste tipo de empresa na modernidade.

Portanto, compreender as características do MEl é também adequar-se a uma nova modalidade de trabalho e emprego. A geração de renda que vem ganhando espaço entre os tipos de enquadramentos empresariais vigentes. Através da análise das características essenciais deste tipo de empreendedor é possível propiciar o surgimento de novos modelos para melhor compreensão dessa dinâmica atual que envolve a cultura do empreendedorismo.

Os momentos constantes e cíclicos de dificuldades político-econômicas do Brasil reforçam a oportunidade da realização de estudos com a temática voltada para o empreendedorismo (Oreiro, 2017), nesse contexto, Soares (2008) afirma que momentos de crise vêm acompanhados de novas formas de trabalho e emprego.

Constata-se a viabilidade do estudo dado ao fato de que em Boa Vista, Roraima existem 8.366 MEls cadastrados (Receita Federal, 2018), ou seja, mais de 80\% da MEl do estado de Roraima estão na capital, Boa Vista, facilitando com isso o acesso aos dados e destacando a possibilidade de obter informações diretamente com os próprios Microempreendedores individuais mesmo com sua recente criação. Há viabilidade também ao considerar o fato da existência de referências sobre o tema.

0 estudo em tela mostra-se relevante, pois o MEl, além de ter sido criado recentemente, é pouco abordado academicamente quando o foco é a região norte, em especial o município de Boa Vista no estado de Roraima. Constata-se a relevância social do estudo uma vez que o resultado da pesquisa poderá ser usado como base para aqueles que estão buscando informações sobre como ingressar na realidade do microempreendedor individual.

Frente à contextualização apresentada e por se tratar de um campo de atuação que está em desenvolvimento, esta pesquisa visa responder a seguinte questão: Quais as características essenciais do microempreendedor individual de Boa vista, Roraima?

Em vias de atender a questão emanada, este estudo tem como objetivo analisar as características essenciais do microempreendedor individual do município de Boa vista, Roraima.

Além desta breve (1) introdução, este artigo este artigo possui também, (2) referencial teórico que busca apontar o estado da arte sobre o tema em questão; (3) procedimentos metodológicos com informações 
a respeito dos procedimentos utilizados para a realização deste estudo; (4) análise de dados que demonstra como os dados foram abordados e empregados nesta pesquisa e a forma de interação dos mesmos no contexto aplicado e, por fim; (5) considerações finais apresentando as principais descobertas da pesquisa.

\section{REFERENCIAL TEÓRICO}

Este tópico é dividido em três seções, (2.1) Empreendedorismo: conceituações e relevância; (2.2) Microempreendedor Individual: histórico, conceitos e legislação e (2.3) Características Essenciais do Microempreendedor: definição e principais características.

\subsection{Empreendedorismo}

Para Dornelas (2014) empreendedorismo é a transformação de ideias em oportunidades, advinda de um conjunto de pessoas que unem forças para alcançar um mesmo objetivo, e, se houver uma implementação dessas oportunidades, pode-se alcançar o status de negócio bem-sucedido.

Neste contexto, Hisrich, Peters e Shepherd (2014) afirmam que o empreendedorismo está na ação de se detectar a oportunidade e agir diante dela, se esta trouxer benefícios condizentes com seus riscos. Com isso, observa-se um consenso capaz de definir, de certa forma, o empreendedor e os comportamentos deste, incluindo entre esses comportamentos, a capacidade de iniciativa, a organização ou reorganização de mecanismos sociais para se beneficiar e, ainda, aceitar os riscos ou os fracassos (Hisrich, Peters e Shepherd, 2009).

Segundo Dornelas (2014), o tema Empreendedorismo vem se tornando algo de extrema relevância para a economia brasileira, pois é um nicho em constante ascensão. Ainda, segundo Dornelas (2014), existem dois tipos de empreendedor, o primeiro, que compreende o conceito inicial de Hisrich et al. (2014), é aquele que reconhece a oportunidade, e com um prévio planejamento busca o sucesso, a riqueza, a criação de empregos e o crescimento da empresa.

O segundo é o empreendedor por necessidade, compreendendo aqueles que se utilizam da criação do negócio próprio não por encontrar uma boa oportunidade ou por se ter uma ideia inovadora, mas sim por precisar, essencialmente, buscar sua subsistência. Esse tipo de empreendimento é o que tende a ter menor grau de sucesso, visto que, geralmente, não há uma ideia, oportunidade clara ou mesmo um objetivo a ser seguido, devido a isto o índice de sucesso dessas é menor. (Dornelas, 2014; SEBRAE, 2016).

Reynolds, Storey e Westhead (1994), em uma pesquisa realizada na Europa, constataram que a criação de novos empreendimentos se dá com maior intensidade em países onde existe maior número de eventos que suportem o novo empreendedor, sejam esses eventos a legislação diferenciada, programas de apoio, tributação diferente etc.

O Poder Público Brasileiro vem adotando essa política de suporte aos empreendedores ao constatar a importância dos novos empreendedores, tanto econômica quanto social, a prova disso está na criação de programas voltados ao empreendedor, como por exemplo, o Programa Brasil Empreendedor, que capacitou no início dos anos 2000 mais de seis milhões de empreendedores e a Lei Complementar $n^{\circ} 128 / 2008$, que criou a figura do MEl (Dornelas, 2014).

\subsection{Microempreendedor Individual}

A Constituição Brasileira de 1988 estabeleceu, nos artigos 170, inciso IX, e 179, que as microempresas e empresas de pequeno porte tivessem um tratamento jurídico diferenciado a fim de amenizar a pesada carga tributária brasileira. Porém, somente com a Lei Complementar no 123/2006, que instituiu o Simples Nacional, tal benefício passou a realmente existir (J ulião, Leone \& Veiga Neto, 2014). Com a implementação do Simples Nacional, em 2007, as microempresas e empresas de pequeno porte tiveram uma redução média de $40 \%$ nos tributos (Portugal, Silva, Portugal Júnior \& Alves, 2017). 
Em 2009 foi instituída a Lei Complementar no 128/2008, que alterou a Lei Complementar no 123/2006 e criou a figura do MEl. Lei esta que concebeu condições distintas para que o trabalhador informal pudesse se tornar um microempreendedor legalizado e usufruir dos mesmos benefícios cujos trabalhadores e empreendedores legalizados possuem (Lopes, Siqueira, Vieira \& Freitas, 2014).

De acordo com a Lei Complementar no 128/2008, MEl é o empresário individual, optante pelo Simples Nacional, que tenha faturamento máximo anual de oitenta e um mil reais ou seis mil e setecentos e cinquenta reais mensais, que não possua mais de um estabelecimento, que possua até um empregado contratado que receba o salário mínimo ou o piso da categoria e que não tenha participação em outra empresa como titular, sócio ou administrador.

Conforme a legislação vigente o MEl terá que recolher um valor fixo mensal de $5 \%$ sobre o salário mínimo vigente referente à Contribuição para a Seguridade Social, mais um real a título de Imposto sobre Operações Relativas à Circulação de Mercadorias e sobre Prestação de Serviços de Transporte Interestadual e Intermunicipal e de Comunicação - ICMS e/ou cinco reais a título de Imposto Sobre Serviços de qualquer Natureza - ISS e ficará isenta de impostos federais (Silva, Lopes, Ribeiro Filho \& Pederneiras, 2010; J ulião et al., 2014; Lopes et al., 2014).

A fim de facilitar a adesão ao $\mathrm{MEl}$, o art. $4^{\circ}$ da Lei Complementar $n^{\circ}$ 139/2011 estipula que "O processo de abertura, registro, alteração e baixa do MEl bem como qualquer exigência para o início de seu funcionamento, deverão ter trâmite especial e simplificado, preferencialmente eletrônico (...)". Desta maneira a formalização do MEl pode ser feita pela internet, de forma gratuita, no Portal do Empreendedor (Silva et al., 2010; Lopes et al., 2014). Caso o MEl não possua acesso à internet, ou não tenha conhecimentos de informática, empresas contábeis estarão realizando esse procedimento de graça. 0 Cadastro Nacional da Pessoa Jurídica CNPJ e o número de inscrição na J unta Comercial são obtidos de imediato (Silva et al., 2010). O SEBRAE (2017) afirma que $27,8 \%$ dos MEls formalizaram-se com a ajuda de um contador.

Julião et al. (2014) alertam que apesar das vantagens o programa traz consigo algumas obrigações e dificuldades para o trabalhador como, por exemplo, dificuldade para realizar uma atualização cadastral ou sair do programa e possíveis exigências como fiança, garantias e limites para o acesso a créditos em bancos.

\subsection{Características Essenciais Do Microempreendedor}

Dornelas (2014), afirma que o perfil do empreendedor ainda não tem uma definição única e objetiva, visto que, à medida que novas obras sobre o tema surgem, inovações sobre o mesmo aparecem.

O perfil do empreendedor para alguns autores, como Cunningham e Lischeron (1991), é maior e mais intrínseco do que o fato de se abrir uma empresa. Ao longo dos anos o empreendedorismo vem sendo debatido e estudado e, em muitas pesquisas, chega-se a algumas características, consideradas essenciais para o empreendedor. Para Hisrich et al. (2009), por exemplo, o empreendedor possui características diferentes das pessoas comuns. Essas características são grande parte da personalidade do empreendedor nato, seja 0 pensamento diferenciado, poder de decisão mesmo em ambientes inseguros e com muitos riscos, e não se importam em dispender o que tem para alcançar os objetivos, seja esse despendimento financeiro ou emocional.

Para Audretsch e Feldman (1996), o espírito empreendedor é capaz de modificar a economia, trazer inovações, buscar mudanças e chegar às novas tecnologias. Para eles, o fato de se empreender força mudanças, sejam tecnológicas, econômicas ou sociais. 0 Global Entrepreneurship Monitor (2013), acrescenta que o empreendedorismo vem crescendo mundialmente, devido a diversos fatores que levam ao caminho do próprio negócio, entre os principais estão a busca de melhores condições de vida e as mudanças existentes no mercado devido às constantes modificações na economia mundial.

0 conjunto de obras que se deu, desde que o tema empreendedor entrou em evidência, trouxe algumas características que são o sumo do que é o empreendedor. Ao estudarem sobre o assunto, Schmidt e Bohnenberger (2009) extraíram de diversos autores as características atitudinais comuns aos empreendedores e as conceituaram. Entre elas estão: assume riscos calculados, planejador, detecta oportunidades, persistente, sociável e inovador. 
Assim, para Schmidt e Bohnenberger (2009), riscos calculados relacionam-se com a análise de variáveis que poderão, dentro de um período, influenciar direta ou indiretamente os resultados esperados. Dornelas (2014) acrescenta que é necessário gerenciar o risco, avaliando as reais chances de sucesso.

Já o planejador, segundo Schmidt e Bohnenberger (2009), é aquele que se prepara para o futuro antevendo aos fatos. Ele faz o planejamento de cada etapa de seu negócio, como rascunhos do plano de negócios, ações de marketing, escolha de fornecedores e etc., utilizando a forte visão de negócio que possui (Dornelas, 2014).

O empreendedor sabe identificar as oportunidades, fazendo bom uso das informações, sejam abstratas, implícitas ou em constante mudança, para aumentar as chances de sucesso do negócio (Schmidt \& Bohnenberger, 2009; Dornelas, 2014).

A persistência está ligada à vontade de alcançar os objetivos, mesmo que isso signifique a privação social. 0 trabalho será intensivo em prol dos objetivos, mesmo que o retorno a este esforço seja incerto. Em outras palavras o grau de comprometimento é máximo, por isso tendem a atropelar as adversidades com sua vontade de "fazer acontecer" (Drucker, 1986; Markman \& Baron, 2003; Souza, Souza, Assis \& Zerbini, 2004; Dornelas, 2014).

Para Hisrich e Peters (2004), o empreendedorismo vem cada vez mais buscando formas de facilitar e impulsionar o andamento dos negócios, para isto utiliza-se de rede social, mantendo sempre o networking em dia, assim poderá manter um círculo de contatos necessários à realização do seu empreendimento. Neste caso faz-se necessário também o uso do carisma pessoal, defendido por McCarthy (2003).

Hisrich et al. (2014) comentam que a função do empreendedor é reformar ou revolucionar o padrão de produção utilizando uma invenção ou método ainda inexistente, para produzir um novo bem ou um bem de maneira diferente.

Uma das tarefas mais difíceis do empreendedor é lançar algo novo, pois além de criar e conceber, ele deve compreender as forças em funcionamento no ambiente. Em suma, segundo Filion (2000), inovador é a pessoa que relaciona ideias, fatos, necessidades e demandas de mercado de forma criativa.

No Quadro 1 é possível verificar as características elencadas pela abordagem utilizada.

\begin{tabular}{|c|c|c|}
\hline Características & Definição & Autores \\
\hline $\begin{array}{l}\text { Assumir riscos } \\
\text { calculados }\end{array}$ & $\begin{array}{l}\text { sGerenciamento dos riscos, diante de um projeto para } \\
\text { avaliar as variáveis que podem influenciar o seu resultado, } \\
\text { decidindo, a partir disso, a continuidade do projeto. }\end{array}$ & $\begin{array}{l}\text { Schmidt \& Bohnenberger (2009) e } \\
\text { Donelas (2014). }\end{array}$ \\
\hline Planejamento & $\begin{array}{l}\text { Ato de planejar o futuro. Planejando cada etapa do seu } \\
\text { negócio. }\end{array}$ & $\begin{array}{l}\text { Schmidt \& Bohnenberger (2009) e } \\
\text { Donelas (2014). }\end{array}$ \\
\hline \begin{tabular}{|l|} 
Detecção \\
oportunidades
\end{tabular} & $\begin{array}{l}\text { Característica de quem detém a predisposição de } \\
\text { explorar, capturar, reconhecer e fazer uso efetivo de } \\
\text { informações em busca de identificar oportunidades. }\end{array}$ & $\begin{array}{l}\text { Markman \& Baron (2003), Schmidt } \\
\& \text { Bohnenberger (2009) e Donelas } \\
\text { (2014). }\end{array}$ \\
\hline Persistência & $\begin{array}{l}\text { Capacidade de trabalhar continuamente em prol do seu } \\
\text { negócio, sujeitando-se em alguns casos a privações } \\
\text { diversas, em projetos de retorno incerto. }\end{array}$ & $\begin{array}{l}\text { Drucker (1986), Markman \& Baron } \\
\text { (2003) e Souza et al. (2004). }\end{array}$ \\
\hline Sociabilidade & $\begin{array}{l}\text { Utilização da rede social para manter um círculo de } \\
\text { contatos necessários à } \\
\text { empreendimento. }\end{array}$ & $\begin{array}{l}\text { McCarthy (2003) e Hisrich \& Peters } \\
(2004) .\end{array}$ \\
\hline Inovação & $\begin{array}{l}\text { Pessoa que faz uso da criatividade para criar ou } \\
\text { reformular um produto ou serviço. }\end{array}$ & $\begin{array}{l}\text { Filion (2000); Schmidt \& } \\
\text { Bohnenberger (2009) e Hisrich et } \\
\text { al. (2014). }\end{array}$ \\
\hline
\end{tabular}

Quadro 1. Características essenciais do microempreendedor.

Fonte: Os autores com base em Drucker (1986); Filion (2000); McCarthy (2003); Markman e Baron (2003); Hisrich e Peters (2004); Schmidt e Bohnenberger (2009); Dornelas (2014); Hisrich et al. (2014). 


\section{PROCEDIMENTOS METODOLÓGICOS}

0 presente estudo utiliza-se do enfoque qualitativo como forma de atender os seus objetivos, isso dado que conforme Leite (2008), a pesquisa qualitativa é aquela que preza pela qualidade da informação e busca utilizar de maneira ad equada os valo res culturais e a capacidade de reflexão do indivíduo. Portanto, cabe ressaltar que não é interesse desta pesquisa extrapolar os dados, ou mesmo tecer inferências para o universo de MEl do estado de Roraima, mas sim, compreender quais são os traços de personalidades a serem observados em análises realizadas com MEl do estado de Roraima.

A decisão por um delineamento qualitativo pelos autores consubstancia-se no fato que trata-se de uma região em que o tema raramente é abordado pela academia, e que dado a inúmeras divergências sociais, culturais e econômicas notórias quando se compara com o restante do país, torna-se necessário, em primeira análise, compreender a configuração atual do cenário que envolve o perfil dos microempreendedores individuais para que, em segunda análise, seja possível verificar a aderência dos elementos teóricos que regem o tema junto a realidade dos MEl do estado de Roraima.

A pesquisa encara o tema em análise de maneira exploratória, visto que, ainda, de acordo com Leite (2008) estudos de abrangência exploratória são aqueles que abordam um tema novo e de material escasso, assim como no caso dos MEls em Boa Vista, Roraima. Foi realizado um levantamento bibliográfico em livros, artigos, sítios eletrônicos etc. Pois, de acordo com Gil (2010), a pesquisa bibliográfica tem o objetivo de fornecer fundamentação teórica ao trabalho.

A pesquisa tem como forma de seleção dos entrevistados a amostragem por conveniência, a qual segundo Gil (2010) é aquela em que o pesquisador seleciona os elementos a que tem acesso, independente da representatividade dos mesmos para o universo em análise. Cumpre-se o destaque para o fato de que dada a característica qualitativa e exploratória do estudo, não se busca a extrapolação dos dados, tal como mencionado por Gil (2010), além disso, o autor aponta ainda que a amostragem por conveniência busca selecionar justamente casos típicos, capazes de oferecer insigths ao pesquisador qualitativo na busca de elementos exploratórios sobre o tema em análise.

Para tanto, a seleção dos entrevistados seguiu os seguintes critérios: contadores que atuam diretamente com MEl; analistas do SEBRAE; e MEls que estejam legalizados há no mínimo um ano. 0 quadro 2 reúne informações a respeito dos entrevistados conforme os critérios de seleção elencados.

\begin{tabular}{|c|l|l|c|c|c|}
\hline Entrevistado & \multicolumn{1}{|c|}{ Função } & Formação acadêmica & $\begin{array}{c}\text { Tempo na } \\
\text { função }\end{array}$ & $\begin{array}{c}\text { Data da } \\
\text { entrevista }\end{array}$ & $\begin{array}{c}\text { Duração da } \\
\text { entrevista }\end{array}$ \\
\hline 1 & Analista do SEBRAE & Bacharel em Administração & 05 anos & $28 / 05 / 2018$ & $10: 24$ \\
\hline 2 & Analista do SEBRAE & Bacharel em Contabilidade & 19 anos & $07 / 06 / 2018$ & $14: 08$ \\
\hline 3 & Analista do SEBRAE & Bacharel em Economia & 02 anos & $13 / 06 / 2018$ & $13: 02$ \\
\hline 4 & Analista do SEBRAE & Bacharel em contabilidade & 06 anos & $18 / 06 / 2018$ & $11: 28$ \\
\hline 5 & MEl & Nível fundamental & 05 anos & $28 / 05 / 2018$ & $14: 20$ \\
\hline 6 & MEI & Nível médio & 03 anos & $10 / 06 / 2108$ & $15: 00$ \\
\hline 7 & MEl & Bacharel em Contabilidade & 06 anos & $18 / 06 / 2018$ & $15: 58$ \\
\hline 8 & MEl & Bacharel em Contabilidade & 03 anos & $19 / 06 / 2018$ & $15: 08$ \\
\hline 9 & Contador & Bacharel em Contabilidade & 23 anos & $12 / 06 / 2018$ & $16: 18$ \\
\hline 10 & Contador & Mestre em Contabilidade & 10 anos & $16 / 06 / 2018$ & $19: 10$ \\
\hline 11 & Contador & Bacharel em Contabilidade & 18 anos & $18 / 06 / 2018$ & $34: 53$ \\
\hline 12 & Contador & Mestre em Contabilidade & 25 anos & $20 / 06 / 2018$ & $20: 57$ \\
\hline
\end{tabular}

Quadro 2. Caracterização dos entrevistados.

Fonte: Os autores (2018).

Para a coleta de dados a técnica utilizada foi a entrevista semiestruturada, que de acordo com Flick (2013) é a entrevista que se utiliza de um guia, e o entrevistador tem liberdade para ditar a direção da 
entrevista, fazendo com que o entrevistado não fique preso a formulação inicial das perguntas, desta forma extraindo o máximo de informações relevantes para a pesquisa.

Quanto ao procedimento escolhido de análise de dados, foi utilizado a análise de conteúdo, que segundo Flick (2013) tem por objetivo classificar o conteúdo das entrevistas alocando as declarações, sentenças ou palavras a um sistema de categorização, permitido assim a realização de análises transversais e obtendo o máximo possível de informações dos dados extraídos da amostra.

Cabe ressaltar que de acordo com Miller e Creswell (2000), a validade da pesquisa qualitativa está voltada para a capacidade do pesquisador em descrever a realidade dos participantes do fenômeno social, bem quanto o mesmo é confiável para eles. Acrescentam ainda Hammersley e Aitkinson (1983) que a qualidade na pesquisa qualitativa não se refere aos dados da pesquisa, mas sim às inferências elaboradas a partir delas.

\section{ANÁLISE DE DADOS}

A coleta de dados ocorreu em maio e junho de 2018 na cidade capital do estado de Roraima, Boa Vista, que tem como principais atividades econômicas, o comércio, a indústria e o serviço. A população da pesquisa foi baseada em contadores, analistas do SEBRAE e MEls, e contou com a participação de 04 profissionais de cada área citada.

Em consonância com o objetivo definido para a realização do trabalho e embasado na perspectiva teórica proposta, buscou-se primeiramente compreender as características do MEl boa-vistense. Para isso uma entrevista realizada relacionou questionamentos que pudessem trazer à tona essas características. Logo, a pergunta inicial foi sobre o que cada entrevistado, independentemente de seu cargo ou função, entendia pelo foco macro do trabalho.

Com as respostas foi possível perceber que todos eles percebiam o tema tal como a abordagem teórica empregada neste estudo, especialmente como observado por Lopes et al. (2014) e a Lei Complementar $n^{\circ} 128 / 2008$ com suas alterações.

Ainda segundo os entrevistados, o MEl geralmente trabalha em atividades em que o valor da movimentação financeira é pequeno, quando comparado com outras modalidades de empresa, sejam vendedores ambulantes, pequenos salões de beleza etc. $0 \mathrm{MEl}$ ou quem está em busca de se formalizar busca esse enquadramento visando aos benefícios àqueles empresários que estão em legalidade, sendo que na informalidade não se obtém nenhum destes benefícios. O quinto entrevistado, sendo um MEI formalizado, destacou que atuar como MEl é também uma forma de "realizar o sonho do negócio próprio".

0 oitavo entrevistado, um MEl formalizado e atuante no ramo de serviços de mecânica há 3 anos, ressaltou que a modalidade de MEl veio para tirar o empreendedor da informalidade e lhe dar uma segurança futura em relação aos benefícios que o mesmo goza, como por exemplo, a aposentadoria, tendo em vista que um empreendedor informal não faz o recolhimento necessário, logo não usufrui de tal direito. Além do mais, a alíquota de recolhimento ao INSS para o MEl é diferenciada, pois a mesma tem um valor reduzido, sendo mais vantajosa quando comparada com as demais modalidades. 0 entrevistado afirmou ainda que o MEl pode aproveitar do direito ao salário-maternidade, auxílio-reclusão, auxílio-doença e pensão por morte.

Após a pergunta inicial, foi questionado quais as características que o Microempreendedor Individual de Boa vista possui, ficando os entrevistados livres para definir essas características. 0 que se buscou foi identificar a visão dos entrevistados em relação às características dos MEls boa-vistenses de maneira espontânea.

Uma característica apontada com relação aos MEl boa-vistense entrevistados, é que todos eles se tornaram microempreendedores individuais ao perderem o seu emprego atual, ou seja, os entrevistados deixaram claro que tornaram MEls por necessidade e não por oportunidades, tal posicionamento é amplamente debatido nas abordagens de Dornelas (2014) quando o mesmo define que muitos se tornam empreendedores não por possuírem qualidades, habilidades ou oportunidades para tal, mas sim, por buscarem sua subsistência. 
O sétimo entrevistado, MEl formalizado e atuante no ramo de comércio, destacou que mesmo com pouco recurso o MEl persiste no empreendimento, pois este acaba se tornando seu único meio para garantir sua subsistência e de sua família.

Em observação às características apontadas de forma espontânea para o MEl de Boa Vista, têm-se de forma crescente 0 empreendimento por necessidade; a busca por reconhecimento legal; a persistência; 0 conservadorismo, pois o mesmo não apresenta como característica dominante a inovação, inclusive, conforme os entrevistados, evita-se a inovação, visto tamanho grau de conservadorismo.

Há ainda, conforme os entrevistados, casos em que o próprio MEl evita o crescimento do empreendimento para não perder algumas vantagens, não olhando tanto para a possibilidade de maior faturamento e maior lucro. Sequencialmente foram apresentadas características atitudinais referentes aos MEls boa-vistenses e foi questionado a eles se essas características representavam ou não as características essenciais desses profissionais em Boa Vista, Roraima.

0 primeiro item trata-se de assumir os riscos calculados pertinentes à atividade empreendedora, como descrito no quadro 1 da página sete, em sua totalidade todos os entrevistados afirmaram que a assunção de riscos calculados se torna a primeira linha de estratégia para a boa manutenção do $\mathrm{MEl}$, sendo, portanto, uma característica de total importância.

Entretanto, seis entrevistados em suas justificativas concluíram que, por mais que seja de total necessidade, o MEl boa-vistense não é um planejador, com isso a assunção de riscos calculados torna-se precária, ou inexistente, como observado pelo entrevistado sete, onde explanou que há a assunção de riscos, porém nem sempre eles são calculados.

O MEl entra no empreendedorismo com a ideia que há total facilidade no negócio, como discorreu o entrevistado dez "acaba se esquecendo que como formalizado, a partir daquele momento deverá assumir várias obrigações, sejam fiscais, trabalhistas etc. E essa falta de cálculo de riscos atinge fortemente os referidos empreendedores quando do término do prazo estipulado em lei para a total regularização do negócio"

Sobretudo, um dos entrevistados, sob a categoria contadores, ressaltou a importância desse item, porém não o classificou como essencial, justificando o fato ao afirmar que o $\mathrm{MEl}$, geralmente, é iniciado por necessidade, logo não há um nível de conhecimento aprofundado sobre o próprio negócio, a persistência, para ele, é mais importante, pois esta que manterá o MEl no mercado de trabalho.

Como observado na perspectiva teórica empregada, o planejamento, seja a curto ou a longo prazo é essencial à boa manutenção da empresa, (Chiavenato, 2003). 0 planejamento a longo prazo é inerente a grandes projetos. 0 curto prazo, então, devido ao valor financeiro movimentado e a forma em que se autopromove o $\mathrm{MEl}$, seria a estratégia mínima requerida à criação de um projeto, fato apontado pelo entrevistado onze, ao ser questionado sobre a essencialidade do planejamento.

Essa foi a segunda característica abordada no estudo, e assim como a assunção de riscos calculados, o planejamento torna-se a primeira etapa para um "bom" empreendimento, visto que sem ele pequenos imprevistos que podiam ser contornados podem acabar tornando-se grandes problemas (Chiavenato, 2003). Neste quesito todos os entrevistados foram unânimes na necessidade e essencialidade deste item.

Sobre o planejamento, afirma um entrevistado sob a categoria de analista do SEBRAE que é, "de vital importância a junção da detecção de oportunidades e a assunção de riscos, pois neste cenário há uma maior chance de sucesso no negócio". Contudo, ao discorrerem sobre a essencialidade do planejamento, entrevistados sob a categoria de contadores e analistas do SEBRAE afirmaram que o mesmo ocorre de forma ínfima por parte dos MEls de Boa Vista, segundo os mesmos, não é uma característica dos MEls de Boa Vista o planejamento, o que, para eles, é, também, péssimo para a economia local, e que tal atitude explicaria a quantidade de fechamentos de MEls nos últimos anos.

Em seguida foi questionado se a detecção de oportunidades é uma característica essencial aos MEls de Boa Vista. Nesse questionamento mais uma vez houve unanimidade da essencialidade deste quesito, visto que, para os analistas do SEBRAE, a deteç̧ão de oportunidades é o primeiro passo, ao lado do planejamento, para que o empreendimento tenha possibilidade de sucesso, e que um negócio começado por uma boa ideia tem mais chances de "dar certo, do que ser mais do mesmo", tal como frisado por um entrevistado sob a categoria contador. 
Discorrendo sobre essa característica a opinião dos entrevistados divergem a respeito da deteç̧ão de oportunidades ser uma característica predominante no MEI de Boa Vista. Dois analistas do SEBRAE definiram que a detecção de oportunidade é inerente ao MEl, pois este ao ver uma oportunidade, pode abrir seu negócio ou até mesmo mudar o ramo do negócio.

Neste cenário, nota-se ainda que há a possibilidade de uma guinada total na forma de oferta de serviços de um MEl de Boa Vista, caso haja uma oportunidade à vista, como destacou o entrevistado dois "muitas vezes ao detectar uma oportunidade o MEl boa-vistense vem ao SEBRAE para se formalizar, pois em muitas situações, como em licitações, há necessidade de que o prestador de serviços esteja formalizado perante a legislação, fisco etc. Sendo assim, o MEl, inclusive, pode se deslocar até para cidades do interior roraimense em busca de uma oportunidade".

Ademais, nota-se das afirmações colhidas que o MEl de Boa Vista pode detectar oportunidades, mesmo que sejam pequenas e distantes, uma vez que outro entrevistado apontou que a detecção de oportunidades é essencial, especialmente quando observado o momento econômico brasileiro, que traz mudanças, estas que podem ser vistas como oportunidades.

Por outro lado, observou-se nas respostas obtidas dos entrevistados que a detecção de oportunidades pelo seguimento de MEl em Boa vista, nem sempre ocorre com a frequência esperada, de modo que o MEI, na definição dessa parcela, não se formaliza ou busca se formalizar por detectar uma oportunidade de negócios e sim por necessidade e que ao se ver desempregado ou em situações que demandem uma decisão que interfira positivamente na sua subsistência busca o MEl, posto a facilidade de sua formalização.

0 próximo questionamento discorreu sobre a persistência, neste caso houve unanimidade, em que foi afirmado que o MEl é persistente e essa característica é essencial. Os entrevistados afirmaram que muitos trabalham arduamente, despendem seus recursos físicos, monetários e emocionais em busca do sucesso comercial mesmo que isso Ihes custe afastamento da família ou amigos, visto que há quem trabalhe todos os dias da semana.

Por vezes, o MEl investe em vários ramos de atividades até prosperar em alguma, informou o sétimo entrevistado. Diferente dos três questionamentos iniciais, este independe de planejamento, oportunidade ou assumir riscos, muitas vezes, segundo os próprios entrevistados "persistir é a única saída, visto que a subsistência do MEl e de sua família estão em jogo". Tal definição vinculada à persistência do MEI, segue a abordagem empregada por Dornelas (2014) e Hisrich et al. (2014) aplicada neste estudo.

Para os entrevistados, em consonância com Longnecker, Moore e Petty (1997), os empreendedores já não podem ser vistos somente como provedores de mercadorias e serviços, em vez disso, eles são vistos como impulsionadores, ou seja, eles impulsionam os colaboradores e o empreendimento. E para tanto, de forma contemporânea, passaram a utilizar das redes sociais, redes de contatos e outras formas virtuais para atingir o público-alvo.

Para os entrevistados o uso das redes sociais e outras formas para se abordar o cliente é importante. Para eles, "por se tratar de marketing barato, o MEl deve buscar cada vez mais este uso e interação". Um analista do SEBRAE entrevistado informou que é comum observar MEls utilizando-se largamente das redes sociais, especialmente aquelas que oferecem facilidade para anúncios e contato com os clientes.

Para um entrevistado da categoria contador, o uso de redes sociais é vital na atualidade, e que dependendo do seu ramo, a não utilização é sinal de perda de clientes, contudo ela ressalta que, por mais que haja essa orientação à exposição dos produtos dos MEl nas redes sociais, o uso ainda se encontra abaixo do esperado.

Notadamente, há quem ainda faça seu networking de forma conservadora. Corroborando a explanação do contador, um entrevistado que é MEl, diz não fazer uso de qualquer rede social, para ele "tratar bem os clientes e ter um bom produto é sinal que voltarão ao meu comércio, sendo assim a forma de socialização é feita cara a cara". Não muito diferente do que fora apontado por outro entrevistado da categoria contador, ele adiciona que o uso dessas ferramentas é importante, mas não essencial, dependendo para tanto, do ramo do negócio, a rede social deve ser usada para dar suporte ao bom produto.

A última característica abordada no estudo foi a inovação, sendo que para todos os entrevistados a inovação é essencial, pois ela é na maioria das vezes a diferença para um grande sucesso. Dornelas (2015), 
afirma que o empreendedor não é estático, não fica à espera de uma ideia ou inovação que mudará tudo, ele é proativo e está sempre em busca de oportunidades. Tal abordagem empregada neste estudo é ratificada pelos entrevistados ao assumirem a essencialidade da inovação.

Para um dos contad ores entrevistados, o brasileiro é inovador, está sempre a um passo de trazer coisas novas, ainda mais quando em períodos de crise financeira, e neste contexto, um MEl entrevistado corrobora com essa visão ao afirmar que todos estão sempre à procura de uma inovação para se ter o sucesso almejado.

Entretanto, tais observações formam um contrassenso quando se verifica a maioria dos respondentes sob as categorias de contadores e analistas do SEBRAE, para eles esse elemento, infelizmente, não é característico do MEl boa-vistense, os entrevistados informam que quando as pessoas decidem se tornar MEI elas buscam atividades e formas de executar essas atividades que sejam familiares a eles, um destes entrevistados afirmou que "os MEls fazem aquilo que sabem fazer, por exemplo, se ele trabalhava em um salão de beleza, ao sair de lá irá, na maioria das vezes, montar seu próprio salão, com pouquíssimas diferenças do local anterior de trabalho".

Após os entrevistados serem questionados sobre as características abordadas, foi perguntado aos mesmos sobre a necessidade de inclusão de outras ainda não consideradas. Destaca-se no Quadro 3 as características e justificativas apresentadas pelos entrevistados, entretanto cabe comentar que alguns entrevistados entenderam que não haviam características para serem adicionadas.

Foram apresentadas ainda algumas características que já haviam sido citadas no referencial teórico, mas com outra denominação como o caso da perseverança, tratada neste estudo como a persistência, sendo neste caso incorporada às abordagens já utilizadas.

Outros elementos também foram sugeridos pelos entrevistados, contudo não foram inseridos na análise em proposição, uma vez que não se tratavam de características atitudinais do $\mathrm{MEl}$, como no caso do elemento marketing pessoal apontado como importante pelos entrevistados, dado que para eles, o cliente pode declinar de uma compra até mesmo pela aparência do vendedor, porém tal sugestão não cabe no escopo desta pesquisa ao considerar que tal elemento faz parte de um conjunto de competências a serem desenvolvidas pelos MEls, e não exatamente uma característica que os mesmos devam possuir.

\begin{tabular}{|c|l|}
\hline CARACTERÍSTICA & \multicolumn{1}{|c|}{ JUSTIFICATIVA } \\
\hline Determinação & $\begin{array}{l}\text { A determinação é essencial para enfrentar problemas e trazer resultados } \\
\text { competitivos ao mercado, a falta de motivação é prejudicial ao MEl. }\end{array}$ \\
\hline Audácia & $\begin{array}{l}\text { O MEl precisa compreender que este enquadramento é temporário, que é como um } \\
\text { começo de um projeto, e que, logo que possível deve alçar voos maiores, caso a } \\
\text { empresa suporte. }\end{array}$ \\
\hline $\begin{array}{c}\text { Busca por } \\
\text { informações }\end{array}$ & $\begin{array}{l}\text { Um MEl com informações tempestivas pode fazer uso para benefício do negócio } \\
\text { próprio, a falta de informações pode acarretar vários problemas como, por } \\
\text { exemplo: falta de pagamento de tributos, contribuições sociais, adição de } \\
\text { funcionários além do permitido e outras situações que poderiam ser evitadas com } \\
\text { uma boa busca por informaçoses. }\end{array}$ \\
\hline
\end{tabular}

Quadro 3. Características do MEl adicionais às apresentadas como essenciais.

Fonte: Os autores (2018).

Em outro caso foi sugerido o elemento assessoria contábil e conhecimento financeiro pelos entrevistados, contudo, por não serem considerados um caso atitudinal, preferiu-se não inserir junto aos elementos abordados no estudo.

Por fim, solicitou-se aos entrevistados que ordenassem as características citadas por ordem decrescente de importância, de 6 (seis) a 1 (um), em que o número mais alto seja o mais importante e o número menor o menos importante. Tal solicitação foi feita para verificar uma possível relação de importância entre as características abordadas.

Quatro dos entrevistados classificaram a característica "detecção oportunidades" com numeral 6, sendo o mais importante dos elementos, pois muitas vezes é a partir daí que o negócio tem início. Em seguida, 
sete dos entrevistados classificaram a característica "planejamento" com numeral 5 , sendo ao lado da detecção de oportunidades os mais importantes. Primeiro detecta-se a oportunidade e logo em seguida faz-se 0 planejamento baseado na oportunidade detectada. Cinco dos entrevistados classificaram a "persistência" com número 4, tendo um grau de importância alto.

Em seguida a característica "assumir riscos calculados" foi classificada por três dos entrevistados com numeral 3, considerado o grau de importância mediano. Já a característica "inovação" foi considerada por quatro entrevistados como tendo um grau de importância de nível baixo, obtendo nota 2. E por fim, a característica "sociabilidade" foi considerada a menos importante entre as apresentadas, tendo recebido número 1 por seis dos entrevistados.

A tabela 1 apresenta os graus de importância das características elencadas neste estudo.

\begin{tabular}{|c|c|}
\hline Características & Grau de importância \\
\hline Detecção de oportunidades & 6 \\
\hline Planejamento & 5 \\
\hline Persistência & 4 \\
\hline Assunção de riscos & 3 \\
\hline Inovação & 2 \\
\hline Sociabilidade & 1 \\
\hline
\end{tabular}

Tabela 1. Grau de importância das características elencadas. Fonte: Os autores (2018).

\section{CONSIDERAÇÕES FINAIS}

É notório que a quantidade de trabalhadores informais vem crescendo anualmente em diversos ramos organizacionais, o que aponta para a possibilidade de a população empreender. A Lei Complementar $n^{\circ} 128 / 2008$, que foi criada em vias de amparar esses trabalhadores, garantindo direitos que até então não lhes eram assegurados, impulsionou a modalidade de MEl no Brasil, e tem ganhado mais espaço no mercado e juntamente pela promoção de maior notoriedade em relação à busca do perfil de seus usuários.

Por conseguinte, o objetivo dessa pesquisa que foi de analisar as características essenciais do microempreendedor individual do município de Boa Vista, Roraima, que foi atendido uma vez que foi possível apresentar um quadro com elementos oriundos da teoria e da prática relacionados às características mencionadas.

Desta forma, através do conteúdo apresentado no referencial teórico, foi elaborado um instrumento de pesquisa para obtenção de dados. De acordo com os dados levantados, percebeu-se que a presença de tais características é essencial aos MEls de Boa Vista. Constatou-se, ainda, o aumento nas chances de 0 empreendimento ter sucesso caso o MEl detenha tais características.

Dessa maneira, as características essenciais para o MEl elencadas são: assunção de riscos calculados, planejamento, detecção de oportunidades, persistência, sociabilidade e inovação. Além das características especificadas no referencial, os entrevistados sugeriram outras características, sendo elas: determinação, audácia e a busca por informações relativas ao MEl. Essas compõem as características essenciais ao MEl boavistense, que resultam deste trabalho.

Entretanto, apesar de ser possível destacar a importância das mesmas para os microempreendedores, observou-se também que muitos têm problemas para lidar com essas questões, ou ainda, para desenvolver caraterísticas que supram as necessidades dos empreendimentos que estão a frente. Isso parece acontecer, principalmente, pelo fato da maioria buscar rapidez na criação da empresa, pulando assim, algumas etapas importantes para o seu negócio como, por exemplo, o planejamento e a assunção de riscos calculados.

Outra dificuldade identificada é o medo de crescer, pois na visão do MEl, o crescimento da empresa acarretará a saída do enquadramento, ocorrendo, então, o pagamento de mais impostos e outras despesas inexistentes ao MEl. 
A pesquisa não buscava exaurir o tema tão complexo, especialmente por lidar com um universo tão vasto como o relacionado ao empreendedorismo, contudo, as características essenciais apresentadas neste trabalho sobre os MEls de Boa Vista, podem refletir também algumas características necessárias dos empreendedores de outras modalidades ou enquadramentos de empresa, ampliando as contribuições propostas no estudo.

Ademais, por ser uma pesquisa qualitativa e tendo como objeto as características essenciais aos MEls boa-vistenses e não o MEl em geral, não se permite a extrapolação dos resultados. Portanto, para estudos futuros sugere-se que esta pesquisa seja desenvolvida utilizando o método quantitativo com o objetivo de verificar se a estrutura de análise proposta se aplica aos MEls de Boa Vista-RR de forma mais ampla. Sugere-se, também, a reaplicação de uma pesquisa qualitativa em outros municípios do Estado de Roraima, para que seja possível verificar se existem divergências entre os resultados em contextos diferentes daqueles abordados neste estudo.

\section{REFERÊNCIAS}

Audretsch, D. B., \& Feldman, M. (1996). $R \& D$ spillovers and the geography of innovation and production. Disponível em: <https://goo.gl/imoJ zo>. Acesso em 16 de janeiro de 2018.

Brasil. Constituição da República Federativa do Brasil de 1988. Disponível em: $<$ http://www.planalto.gov.br/ccivil_03/constituicao/constituicao.htm>. Acesso em: 04 de abril de 2018.

Brasil. Lei Complementar $N^{\circ} 123 / 2006$, de 14 de dezembro de 2006. Institui o estatuto nacional da microempresa e da empresa de pequeno porte e dá outras providências. Disponível em: <http://www.planalto.gov.br/ccivil_03/Leis/lcp/lcp123.htm>. Acesso em 02 de março de 2018.

Brasil. Lei Complementar $N^{\circ} 128 / 2018$, de 19 de dezembro de 2008. Dispõe sobre os MEls. Disponível em: <http://www.planalto.gov.br/ccivil_03/Leis/LCP/Lcp128.htm>. Acesso em 02 de fevereiro de 2018.

Brasil. Lei Complementar № 139, de 10 de novembro de 2011. Altera dispositivos da Lei Complementar no 123, de 14 de dezembro de 2006, e dá outras providências. Disponível em: < http://www.planalto.gov.br/ccivil 03/Leis/lcp/Lcp139.htm>. Acesso em 05 de fevereiro de 2018.

Chiavenato, I. (2003). Introdução à teoria geral da administração: uma visão abrangente da moderna administração das organizações (7ạ ed.). Rio de J aneiro: Elsevier.

Cunningham, J. B., \& Lischeron, J. (1991). Defining entrepreneurship. Journal of Small Business Management, 29, p. $45-61$.

Dornelas, J. C. (2014). Empreendedorismo: transformando ideias em negócios (5a ed.). Rio de Janeiro: Empreende/ LTC.

Dornelas, J. C. (2015). Empreendedorismo corporativo: como serempreendedor, inovar e se diferenciar na sua empresa ( 3 a ed.). Rio de Janeiro: LTC.

Drucker, P. F. (1986). Inovação e espírito empreendedor (entrepreneurship): práticas e princípios. São Paulo: Thompson/Pioneira.

Filion, L. J. (2000). Empreendedorismo e gerenciamento: processos distintos, porém complementares. Disponível em: <http://www.scielo.br/scielo.php?script=sci_arttext\&pid=S0034-75902000000300013>. Acesso em 14 de Janeiro de 2018.

Flick, U. (2013). Introdução à metodologia de pesquisa: um guia para iniciantes (1a ed.). Porto Alegre: Penso.

Gil, A. C. (2010). Como elaborar projetos de pesquisa (5a ed.). São Paulo: Atlas.

Gil, A. C. (2010). Métodos e técnicas de pesquisa social (6a ed.). São Paulo: Atlas.

Global Entrepreurship Monitor. (2013). Empreendedorismo no Brasil. Curitiba: IBQP.

Hashimoto, M. (2006). Espírito empreendedor nas organizações: Aumentando a competitividade através do intraempreendedorismo. São Paulo: Saraiva.

Hisrich, R. D., \& Peters, M. P. (2004). Empreendedorismo (5a ed.). Porto Alegre: Bookman.

Hisrich, R. D., Peters, M. P., \& Shepherd, D. A. (2009). Empreendedorismo (7a ed.). Porto Alegre: Bookman. Hisrich, R. D., Peters, M. P., \& Shepherd, D. A. (2014). Empreendedorismo (9a ed.). Porto Alegre: AMGH.

Instituto Brasileiro de Geografia e Estatística - IBGE. (2008). Índice de trabalho e rendimento/economia informal urbana. Disponível em:

<ttp://ftp.ibge.gov.br/Trabalho_e_Rendimento/Economia_Informal_Urbana/2003/Brasil/>. Acesso em 03 de janeiro de 2018.

Julião, F., Leone, R.J. G., \& Veiga Neto, A. R. (2014). Fatores determinantes da satisfação de usuários do programa microempreendedor individual. Disponível em: 
$<$ <ttp://www.spell.org.br/documentos/ver/31150>. Acesso em 15 de janeiro de 2018.

Leite, F. T. (2008). Metodologia científica: métodos e técnicas de pesquisa: monografias, dissertações, teses e livros (2a ed.). São Paulo: Ideias e Letras.

Longenecker, J. G., Moore, C. W., \& Petty, J. W. (1997). Administração de pequenas empresas: ênfase na gerencia empresarial. São Paulo: Makron Books.

Lopes, L. C., Siqueira, K. P. S., Vieira, E. M. M., \& Freitas, M. A. L. (2014). Adoção de práticas de controles financeiros e não financeiros por microempreendedores individuais. Disponível em:

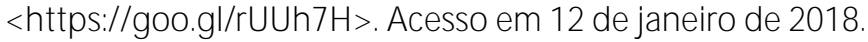

Maloney, W. F. (1999). Does informality imply segmentation in urban labor markets? Evidence from sectoral transitions in Mexico. Disponível em: <https://goo.gl/L7Np7f>. Acesso em 08 de janeiro de 2018.

Markman, G. D., \& Baron, R. A. (2003). Person-entrepreneurship fit: why some people are more successful as entrepreneurs than others. Disponível em: $<$ https://www.sciencedirect.com/science/article/pii/S1053482203000184>. Acesso em 12 de janeiro de 2018.

Mccarthy, B. (2003). The impact of the entrepreneur's personality on the strategy-formation and planning process in SME. Disponível em: <https://goo.gl/tKEDuX>. Acesso em 10 de janeiro de 2018.

International Labour Office. (2018). Women and men in the informal economy: a statistical Picture. (3a edição). Geneva: ILO.

Oliveira, F. (2005). Crítica à razão dualista: o ornitorrinco. São Paulo: Boitempo.

Oreiro, J. L. (2017). A grande recessão brasileira: diagnóstico e uma agenda de política econômica. Disponível em: <http://www.scielo.br/scielo.php?script=sci_arttext\&pid=S0103-40142017000100075>. Acesso em 13 de janeiro de 2018.

Portugal, N. S., Silva, S. S., Portugal Júnior, P. S. \& Alves, A. F. (2017). Microempreendedores individuais: um estudo sobre suas ações e percepções frente às exigências do desenvolvimento sustentável. Disponível em: <https://goo.gl/j9mqlt>. Acesso em 12 de janeiro de 2018.

Receita Federal do Brasil. (2018). Relatórios estatísticos. Disponível em: <http://www22.receita.fazenda.gov.br/inscricaomei/private/pages/relatorios/opcoesRelatorio.j sf\#>. Acesso em 30 de junho de 2018.

Reynolds, P. D., Storey, D. . ., \& Westhead, P. (1994). Cross national comparison of the variation on the new firm formation rates. Disponível em: <https://www.tandfonline.com/doi/abs/10.1080/00343409412331348386>. Acesso em 12 de janeiro de 2018.

Schmidt, S., \& Bohnenberger, M. C. (2009). Perfil empreendedor e desempenho organizacional. Disponível em: <http://www.scielo.br/scielo.php?pid=S1415- 65552009000300007\&script=sci_abstract\&tlng=es>. Acesso em 03 de março de 2018.

Serviço Brasileiro de Apoio às Micro e Pequenas Empresas - SEBRAE. (2016). Perfil do microempreendedor individual 2015. Disponível em: <http://datasebrae.com.br/wp- content/uploads/2017/03/Perfil-doMicroempreendedor-Individual-2015-Final.pdf>. Acesso em 03 de abril de 2018.

Serviço Brasileiro de Apoio às Micro e Pequenas Empresas - SEBRAE. (2017). Pesquisa MEI 2017. Disponível em: <http://www.sebrae.com.br/Sebrae/Portal\%20Sebrae/UFs/SP/Pesquisas/SEBRAE-SP\%20\%20MEl\%202017\%20-\%20Relatorio\%20Final-Imprensa.pdf>. Acesso em 03 de abril de 2018.

Serviço Brasileiro de Apoio às Micro e Pequenas Empresas - SEBRAE. (2018). Perfil do MEl. Disponível em: $<$ http://datasebrae.com.br/perfil-do- microempreendedor-individual/\#infografico >. Acesso em 03 de abril de 2018.

Silva, A. B., Lopes, J. E. G., Ribeiro Filho, J. F., \& Pederneiras, M. M. M. (2010). Um estudo sobre a percepção dos empreendedores individuais da cidade de Recife quanto à adesão a Lei do micro empreendedor individual (Lei MEl 128/08). Disponível em: <http://www.spell.org.br/documentos/ver/5880/um-estudosobre-a-percepcao-dos- empreendedores--->. Acesso em 18 de fevereiro de 2018.

Soares, M. A. T. (2008). Trabalho informal: da funcionalidade à subsunção ao capital. Vitória da Conquista, BA: Editora da UESB.

Souza, E. C. L., Souza, C. C. L., Assis, S. A. G., \& Zerbini, T. (2004). Métodos e técnicas de ensino e recursos didáticos para o ensino do empreendedorismo em IES brasileiras. Anais do Encontro Nacional da Associação Nacional de Pós-Graduação e Pesquisa em Administração, Curitiba, PR, Brasil, 28. 